\title{
Optimization Analysis and Implementation of Online Wisdom Teaching Mode in Cloud Classroom Based on Data Mining and Processing
}

\author{
https://doi.org/10.3991/ijet.v16i01.18233 \\ Jing Gao \\ Wuhan Business University, Wuhan, China \\ Xiao-Guang Yue \\ European University Cyprus, Nicosia, Cyprus \\ Lulu Hao $(\varpi)$ \\ Cultural Tourism Industry Research Center, Wuhan, China \\ haolulu8870@126.com \\ M. James C. Crabbe \\ Oxford University, Oxford, UK \\ University of Bedfordshire, Luton, UK \\ Shanxi University, Taiyuan, China \\ Otilia Manta \\ Romanian Academy, Center for Financial and Monetary Research-Victor Slăvescu, \\ Bucharest, Romania \\ Romanian-American University, Bucharest, Romania \\ Nelson Duarte \\ Politécnico do Porto, Felgueiras, Portugal
}

\begin{abstract}
The rapid development of Internet technology and information technology is rapidly changing the way people think, recognize, live, work and learn. In the context of Internet + education, the emerging learning form of a cloud classroom has emerged. Cloud classroom refers to the process in which learners use the network as a way to obtain learning objectives and learning resources, communicate with teachers and other learners through the network, and build their own knowledge structure. Because it breaks the boundaries of time and space, it has the characteristics of freedom, high efficiency and extensiveness, and is quickly accepted by learners of different ages and occupations. The traditional cloud classroom teaching mode has no personalized recommendation module and cannot solve an information overload problem. Therefore, this paper proposes a cloud classroom online teaching system under the personalized recommendation system. The system adopts a collaborative filtering recommendation algorithm, which helps to mine the potential preferences of users and thus complete more accurate recommendations. It not only highlights the core position of personalized curriculum recommendation in the field of
\end{abstract}


online education, but also makes the cloud classroom online teaching mode more intelligent and meets the needs of intelligent teaching.

Keywords-Internet technology, Cloud classroom, Teaching mode, Online teaching system, Smart teaching

\section{Introduction}

The mobile Internet and smart terminals are widely popularized, and Internet + has gradually become a new trend in economic development. The cloud classroom learning system consisting of Internet + Education, including mobile learning, ubiquitous learning, and virtual learning, greatly enriches the students' network-based learning style, so that students may freely choose their own satisfactory methods for deeper learning based on their interests. A cloud classroom is a product of the era of big data, with its own unique information technology advantages [1]. At present, with the gradual and wide application of new technologies such as cloud computing, big data, Internet, and mobile computing, the pace of informationization in various economic and social industries is accelerating, and the overall informationization of society is deepening. The revolutionary impact of information technology on education is becoming increasingly apparent. As the main element of school teaching, classroom teaching, a deep integration of information technology and classroom teaching is the core and the key to a comprehensive integration of information technology and education. It promotes the quality of education and promotes educational fairness and equality at a higher level. Accelerating the process of education modernization is of great practical significance. In the current era of cloud computing, we have seen the characteristics of cloud education sharing, integration, dynamics, intelligence and the power of service education and teaching. Under the shower of cloud education, the cloud computing integration classroom teaching has entered peoples' field of vision with the attitude of online cloud classroom teaching, and has received extensive attention. At the same time, the cloud classroom also breaks with limitations of time and space, and can specify a personalized learning program for learners, making lifelong learning possible [2]. On the basis of online learning, some new learning methods, such as mobile learning, ubiquitous learning, and virtual learning have been enriched, which greatly enhances the students' network-based learning methods, so that students may freely choose their own satisfactory methods for interest-based learning. Now in-depth study can really mean learning.

Cloud classroom teaching is a form of both synchronous teaching and asynchronous teaching that breaks through time and space constraints. This form emphasizes the organization of the teaching place (space). It can be used alone to conduct cloud classroom learning anytime, anywhere. This is manifested in the form of asynchronous teaching. If it is to participate in learning through the form of live broadcasts, it also appears as a synchronous teaching form. Under normal circumstances, in order to achieve better teaching results, cloud classroom teaching and offline classroom teaching are combined to carry out teaching work, which is expressed as a synchronous 
teaching form. The teaching content is derived from the teaching resources that teachers push or upload, including teaching videos, electronic text materials, quality courses, pictures and courseware [3]. The teaching content carrier is a cloud classroom teaching platform, which is a learning course management system platform. The learner downloads and installs the client of the platform, and can log in to the platform of the learning course according to the specific account password. Both teachers and students must enter the cloud classroom teaching platform to achieve teaching and learning. Teachers log on to the cloud classroom teaching platform, create and upload the required courseware and instructional videos for students to learn online and offline. Teachers can conduct course management, teaching evaluation, tracking student learning progress, homework corrections, online Q\&A and discussion. Students can $\log$ in to the cloud classroom teaching platform to achieve fast sign-in, resource sharing, learning instructional videos, exercise exercises, teacher-student interactions, and more.

The implementation process of cloud classroom teaching is shown in Figure 1:

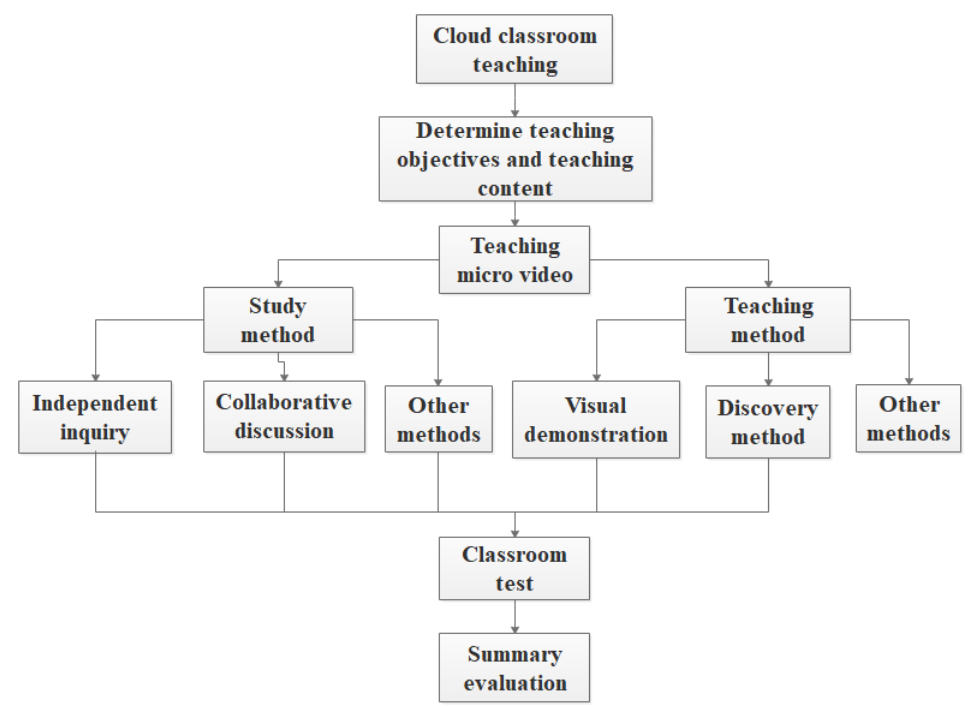

Fig. 1. Cloud classroom teaching implementation process diagram.

\section{Cloud Classroom Teaching Mode}

The wisdom teaching mode emphasizes personalized recommendation. The research on a personalized recommendation system and online teaching can ensure that users can conduct multiple learnings on the same platform, avoiding time and space troubles and improving students' learning efficiency. Choosing the appropriate recommendation algorithm is the core of online classroom intelligent teaching [4]. Based on data mining and processing technology, this paper studies the coupling analysis between a personalized recommendation algorithm and the cloud classroom 
online teaching mode, and realizes the improvement of the function of online teaching platform and the improvement of user experience, which makes the online teaching system more perfect.

The cloud classroom online learning platform not only provides an online learning environment, but also has the following characteristics:

1. Simple operation and low technical requirements. Teachers and students do not have to spend too much time to master the basic operations of the cloud classroom.

2. The cloud classroom has a powerful teaching function. The teacher can flexibly organize various functional modules according to the actual mixed teaching needs, so as to achieve the purpose of transmitting the teaching content, supporting the teaching activities, evaluating the teaching effect, and completing the established teaching objectives.

3. A cloud classroom has powerful interactive functions. The cloud classroom online learning platform forum, chat room, notification, homework and other modules can help the development of mixed learning interaction activities. Teachers can use these functions to organize collaboration, exchange discussions, and arrange tasks, improving online learning interaction and emotional communication. This means the interaction between teachers and students, as well as students and students can be easily realized.

A cloud classroom online learning platform is shown in Figure 2.

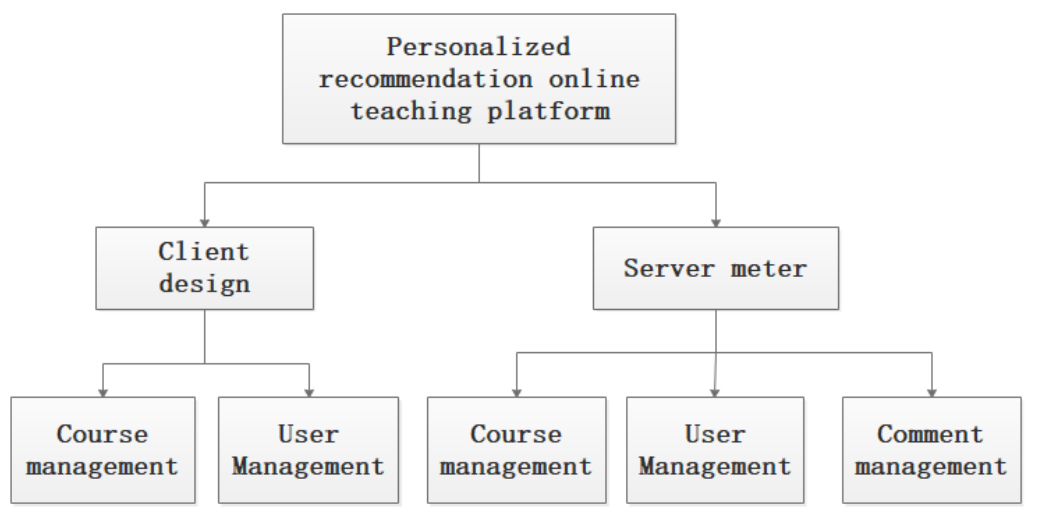

Fig. 2. Cloud classroom online learning platform diagram.

\subsection{Online course optimization analysis}

With the rapid growth of online education, information has changed from text form to multimedia form including pictures, audio, video, and online live broadcasts. The quality of information and how to identify the required information have become urgent problems to be solved. Especially in the fast pace of work and study, the accuracy and speed of information acquisition is particularly important [5]. In such a social environment, providing students with accurate and efficient information has be- 
come the most important task of cloud classroom online teaching. In response to such situations, the domestic cloud classroom website has made some simple responses, but in most cases, users are not very clear about what they really want. Many of the above issues have contributed to the development of emerging technologies and have resulted in personalized recommendation techniques to address the accuracy and efficiency of information acquisition. The core idea is to recommend the information that users really need to meet the characteristics of different users. To achieve this, many cloud classroom websites have personalized recommendations as the main push in order to enhance the user experience. As an effective means to solve information overload, personalized recommendation is also of great significance to the online education platform. At present, most of the personalized recommendation systems adopt the collaborative filtering recommendation algorithm. Compared with other traditional algorithms, the biggest advantage of the collaborative filtering recommendation algorithm is that it is applicable to use unstructured objects. Most of the personalized recommendation systems adopt the collaborative filtering recommendation algorithm, which is the most popular recommendation technology and the most widely used recommendation technology. It is also an important current research direction in the field of recommendation algorithms.

\subsection{Algorithm model}

Research on a personalized recommendation system is mainly based on a collaborative filtering recommendation algorithm, a content-based recommendation algorithm and a context-aware recommendation algorithm [6]. Through in-depth study of several algorithms, through repeated experiments, we have combined several recommended system algorithms to provide users with recommendations for personalized courses. The model structure is shown in Figure 3.

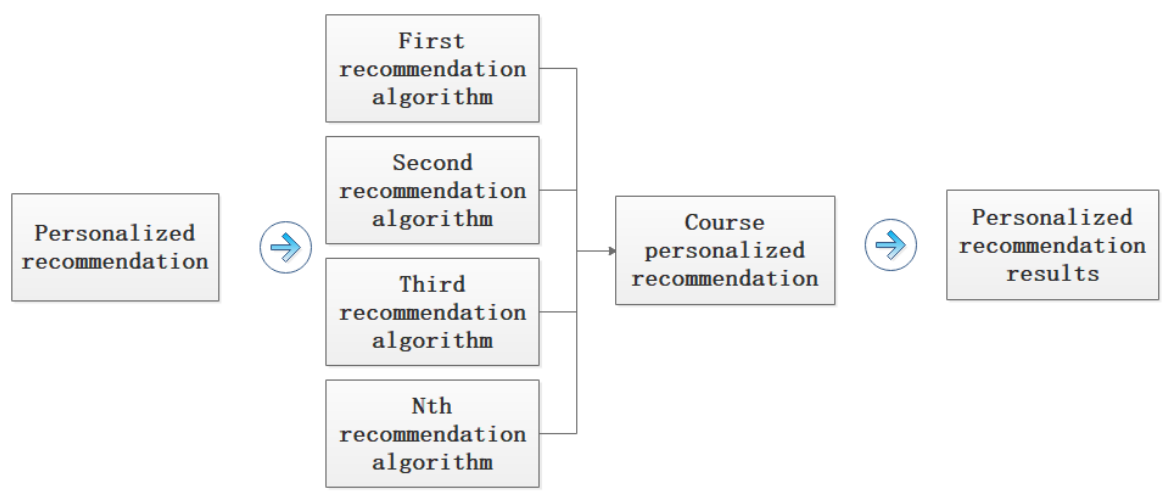

Fig. 3. Personalized recommendation algorithm set model diagram. 


\subsection{User-based recommendation}

The purpose of the system is to recommend interest and items that need to rely on different media to contact the user. At present, there are three ways to do this. First, through the user's past records, recommend similar products to the users based on the items they like. The second is to find similar users and recommend other similar user preferences to the target users. The third is to link users and items through some characteristics, and recommend items with similar characteristics to the target users. Features can be expressed in a variety of ways, such as an attribute model of an item, or an implicit semantic vector, followed by a label. A tag is a non-hierarchical structure that describes the information and can also describe the semantics of the item. Label applications are usually divided into two types, depending on who is tagging the project. One is the label given by the official author or professional, and the other is the label of the individual user's project, that is, UGC (Unique Games Conjecture)'s label application, which is an important way to express user interest and item semantics. When a user tags an item, the behavior describes the semantics of the item while describing the user's preferences, thereby associating the user with the item [7]. The labeling system is currently widely used in websites of various industries. Accurate description of item keywords according to the wisdom of the population is a huge advantage of the labeling system. Accurate content has become an important guarantee for improving the performance of personalized recommendation systems. As an important user behavior that covers many user preferences, its simple form and easy to use features provide possibilities for in-depth research.

\subsection{Content-based recommendation}

Content-based recommendation is one of the first developments in recommendation technology. The core is to recommend information resources with similar content, which is the essence of the recommendation system. One can recommend similar projects to target users, which can achieve the effect of accurate recommendation. The recommended process of this technology is shown in Figure 4. First, the user's past behavior record information should be mined. After analysis, a user interest model is built according to the content. Through the similarity process with other projects or other models, this model is continuously trained in the process, and the similarity calculation result is used to make accurate recommendation. This technology is mature in the field of information recommendation at the text level [8]. The recommendation process is simple and clear, which saves complicated operations and plays a vital role in text information recommendation. Content-based recommendation mode is shown in Figure 4.

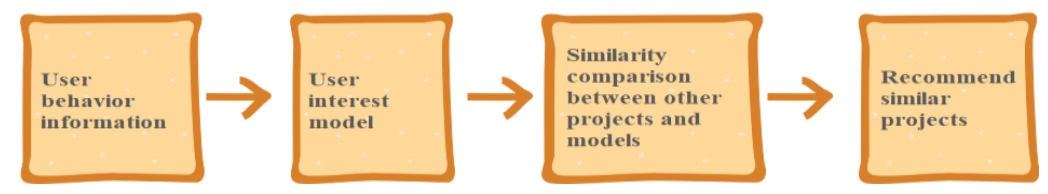

Fig. 4. Content-based recommendation flow chart. 


\subsection{Recommended based on collaborative algorithms}

Collaborative filtering is the most popular recommendation algorithm. The core idea is that users who have the same or similar interests in the past will have the same interest in the future. The recommended algorithm for the basic model is based on sample data. The user evaluation matrix is used to predict the model parameters, the recommendation model is trained, and then the recommendation prediction is performed according to the real-time user preference information. The main idea of matrix decomposition is to approximate the original scoring matrix with two low rank matrices. The approximate loss function minimizes the sum of squared errors between the prediction matrix (the product of the two lower-order matrices) and the original fractional matrix. Collaborative filtering finds the user's neighbors of the current user based on the user's rating data, and then recommends relevant items that are preferred by the neighboring users for the current user [9]. The basic idea of the collaborative filtering recommendation method is that if the user has a good impression of the same project, the user who has similar interests with the user may also have a certain affection for the project. First, the algorithm collects and analyzes the user's historical behavior and project evaluation information, and obtains the user's interest preference information. Then, the system searches for users who have similar interests with the target user, calculates their similarity by some methods, and selects the user with high similarity as the target user's neighbor score to predict the target user's score, thereby realizing the target user's recommendation.

This paper adopts a content-based collaborative filtering recommendation algorithm and a hybrid optimization recommendation algorithm based on it. The contentbased collaborative filtering recommendation algorithm uses the scoring matrix to calculate the similarity between users or projects, and recommendations based on the similarity relationship between projects or users.

1. Pearson correlation coefficient:

$$
\operatorname{sim}(u, v)=\frac{\sum_{i \in I_{a} \cap I_{v}}\left(r_{u, i}-\bar{r}_{u}\right) \cdot\left(r_{v, i}-\bar{r}_{v}\right)}{\sqrt{\sum_{i \in I_{u} \cap I_{v}}\left(r_{u, i}-\bar{r}_{u}\right)^{2}} \cdot \sqrt{\sum_{i \in I_{u} \cap I_{v}}\left(r_{v, i}-\bar{r}_{v}\right)^{2}}}
$$

2. Cosine similarity:

$$
\operatorname{sim}(u, v)=\cos (\vec{u}, \vec{v})=\frac{\vec{u} \cdot \vec{v}}{\|\vec{u}\| \cdot\|\vec{v}\|}=\frac{\sum_{i \in I_{n} \cap l_{v}} r_{u, i} \cdot r_{v, i}}{\sqrt{\sum_{i \in I_{u} \cap I_{v}} r_{u, i}^{2}} \cdot \sqrt{\sum_{i \in I_{u} \cap I_{v}} r_{v, i}^{2}}}
$$


3. Correct the cosine similarity:

$$
\operatorname{sim}(u, v)=\frac{\sum_{i \in I_{u} \cap I_{v}}\left(r_{u, i}-r_{i}\right) \cdot\left(r_{v, i}-r_{i}\right)}{\sqrt{\sum_{i \in I_{u} \cap I_{v}}\left(r_{u, i}-\overline{r_{i}}\right)^{2}} \cdot \sqrt{\sum_{i \in I_{u} \cap I_{v}}\left(r_{v, i}-\bar{r}_{i}\right)^{2}}}
$$

Sim (u, v) represents the similarity between users u, v, IU, IV, respectively, representing the collection of items scored by user $\mathrm{u}, \mathrm{v}$.

\subsection{Optimization algorithm design}

A user-based collaborative filtering method is used to mine the past behavior of the target user. Browse and collect projects to gain insight into what users like, mine preference information, then search the system for users with similar preferences to users, and use formulas to calculate similarities between users and users. Then, the specified number of adjacent users are intercepted by the similarity size order, and the target user's score on an item is predicted according to the rating value of the adjacent user for a certain item. After listing the structure, the user is asked to extract the item with a higher predicted score [10]. Since there are no complicated restrictions, many situations can be matched, and many abstract projects can be handled well to discover user preferences. The user rating information used by the user-based collaborative filtering method is a specific explicit value. Identifying similar users of the target user is the most important part of the process and a prerequisite for further prediction and recommendation.

1. Cosine similarity

$$
\operatorname{sim}_{u v}=\cos (u, v)=\frac{\sum_{i \in I_{w}} r_{u i} r_{v i}}{\sqrt{\sum_{i \in I_{u}} r_{u i}} \sqrt{\sum_{i \in I_{v}} r_{v i}^{2}}}
$$

2. Modified cosine similarity

$$
\operatorname{sim}_{u v}=\frac{\sum_{i \in I_{m}}\left(r_{u i}-\bar{r}_{u}\right)\left(r_{v i}-\bar{r}_{v}\right)}{\sqrt{\sum_{i \in I_{u}}\left(r_{u i}-\bar{r}_{u}\right)^{2}} \sqrt{\sum_{i \in I_{v}}\left(r_{v i}-\bar{r}_{v}\right)^{2}}}
$$

\section{Pearson similarity}

In practice, there are often two users who have the same judgment on the same project. But there are some differences in the score. Pearson's similarity formula can be 
used to resolve inconsistencies between users. In this case, when the user similarity is calculated, it is necessary to first consider whether the information in the past rating record has a linear relationship. If there is, the similarity is confirmed; if not, the similarity is invalid. Compared with the modified cosine similarity, the former is based on the commonly used scoring items between users, and the latter is based on the user's own scoring items. The calculation formula (6) is as follows:

$$
\operatorname{Sim}_{u v}=\frac{\sum_{i \in I_{w}}\left(r_{u i}-\bar{r}_{u}\right)\left(r_{v i}-\bar{r}_{v}\right)}{\sqrt{\sum_{i \in I_{m}}\left(r_{u i}-\bar{r}_{u}\right)^{2}} \sqrt{\sum_{i \in I_{w}}\left(r_{v i}-\bar{r}_{v}\right)^{2}}}
$$

In the system, a recommendation algorithm based on collaborative filtering is used, and according to the search content of the target user, the neighboring users are judged, and the appropriate course is recommended for the user according to the past records of the similar users.

\section{Design of Smart Teaching System}

\subsection{System development environment}

Operating system: Windows 7.

Development language: C\#, HTML_5.

Development Tools: Microsoft Visual Studio 2017, HBuilder.

Database version: QL Server 2014.

Server version: Apache 5.1.28-rc-communit.

\subsection{System platform design}

This research is a personalized online teaching platform based on a collaborative filtering algorithm. The main goal is to break the limitations of time and space, increase the way users learn, and use the enthusiasm of new users to improve the learning efficiency of users [11]. Online learning is a popular learning method that allows students who do not have time or attend the face-to-face courses to learn and learn the required knowledge through online courses. It is also an important method for learning during viral pandemics, like that with Covid-19.

The design of each functional module includes the design of the login function module, the design of the teacher information display module, the course information display module and the online live course function.

1) Login module design: In the login interface, it is determined whether the user is registered. The registered user passes the verification login name, password and verification code. The platform: Unregistered users need to register, and select the 
teacher identity when registering. After the verification is passed, the registration is successful.

Table 1. Login module design

\begin{tabular}{|l|l|l|}
\hline \multicolumn{1}{|c|}{ Attributes } & \multicolumn{1}{|c|}{ Specific contents } & \multicolumn{1}{c|}{ Description } \\
\hline Actor & Student number & Use student number to distinguish each student \\
\hline \multirow{4}{*}{ Veb } & Login & Student login behavior, learning unit or other module behavior \\
\cline { 2 - 3 } & View & $\begin{array}{l}\text { Student view content in courseware, learning activities or } \\
\text { notifications, statistics module }\end{array}$ \\
\cline { 2 - 3 } & Comment & Student's comment on the forum \\
\cline { 2 - 3 } & Submit & Student submitting assignments \\
\cline { 2 - 3 } & Download & Student download courseware and other behaviors \\
\hline
\end{tabular}

2) Teacher information module design: The teacher information entered in the database is displayed in the module. The student can click on the teacher picture to enter the teacher information page, and intuitively see the teacher style and the teacher teaching experience. The direction of the lecture and the operation is convenient, and the student can understand the required information.

Table 2. Teacher information module design

\begin{tabular}{|l|l|l|}
\hline Attributes & Specific contents & \multicolumn{1}{c|}{ Description } \\
\hline \multirow{5}{*}{ Object } & Course & Students click to log in to a course, course id \\
\cline { 2 - 3 } & Course unit & In the resource module, the student enters a unit, unit id \\
\cline { 2 - 3 } & Courseware & In the resource module, the courseware id that the student learns \\
\cline { 2 - 3 } & Learning activities & Learning activity is viewed by the student \\
\cline { 2 - 3 } & Notice & Notification is for student browsing \\
\cline { 2 - 3 } & Operation & Student's job id \\
\cline { 2 - 3 } & Member & Member module id \\
\cline { 2 - 3 } & Statistics & Statistics module id \\
\hline
\end{tabular}

3) Course information module design: The course information entered in the database is displayed on both the teacher login page and the student login page [12]. Students can intuitively see the course name and the lecturer information, and the main content through the course information. 
Table 3. Course summary

\begin{tabular}{|l|l|l|l|}
\hline \multicolumn{1}{|c|}{ Project } & \multicolumn{1}{|c|}{ Claim } & Media form & Attributes \\
\hline $\begin{array}{l}\text { Course } \\
\text { Introduction }\end{array}$ & $\begin{array}{l}\text { The basic information of the course includes the course catego- } \\
\text { ry, suitable for majors, hours and credits, the nature and charac- } \\
\text { teristics of the course, and materials and reference materials. }\end{array}$ & Text & Must choose \\
\hline Course guide & $\begin{array}{l}\text { Course teaching methods, teaching activities and learning } \\
\text { support services }\end{array}$ & $\begin{array}{l}\text { Text } \\
\text { The class outline defines the teaching content of the course in } \\
\text { the form of outline, and its body should include the purpose of } \\
\text { Course } \\
\text { outline }\end{array}$ & $\begin{array}{l}\text { content, the module or unit aspiration target and task, the teach- } \\
\text { ing activity, and the procedural requirements of the course. }\end{array}$ \\
\hline $\begin{array}{l}\text { Teaching } \\
\text { calendar }\end{array}$ & $\begin{array}{l}\text { The teaching calendar is the specific implementation plan of the } \\
\text { organization of the course teaching, and should clearly define } \\
\text { the teaching process, teaching content, homework, teaching } \\
\text { methods, etc. }\end{array}$ & Text & Must choose \\
\hline
\end{tabular}

4) Online live course module design: All information about the live online course will be displayed in this module. In this module, you can check the course information [13 14]. One can view the introduction of the online course, the course teacher, the course time and class hours, and the course fee. Students can join the online course purchase.

Table 4. Course module

\begin{tabular}{|c|c|c|c|}
\hline Project & Claim & $\begin{array}{c}\text { Media } \\
\text { form }\end{array}$ & Attributes \\
\hline $\begin{array}{l}\text { learning } \\
\text { target }\end{array}$ & Provide specific, clear module learning objectives & Text & Must choose \\
\hline $\begin{array}{l}\text { knowledge } \\
\text { structure }\end{array}$ & $\begin{array}{l}\text { Provide the main knowledge points and content organization } \\
\text { structure contained in the chess piece, and use the knowledge } \\
\text { structure diagram to represent the concept map. }\end{array}$ & Image & Must choose \\
\hline $\begin{array}{l}\text { Learning } \\
\text { advice }\end{array}$ & $\begin{array}{l}\text { Provide valuable learning suggestions and help for the key and } \\
\text { difficult content of the course, and have clear instructions for } \\
\text { various learning activities and learning methods, and are detailed } \\
\text { and appropriate. }\end{array}$ & $\begin{array}{l}\text { Text or } \\
\text { video }\end{array}$ & Must choose \\
\hline $\begin{array}{l}\text { Learning } \\
\text { Content }\end{array}$ & $\begin{array}{l}\text { The content of the course is presented in multimedia format such } \\
\text { as text, graphics/images, sounds, visuals, animations, etc. The } \\
\text { media format is suitable for learners and learning content. }\end{array}$ & Multimedia & Must choose \\
\hline $\begin{array}{l}\text { Teaching } \\
\text { video }\end{array}$ & $\begin{array}{l}\text { Recorded by teaching unit or knowledge point, including com- } \\
\text { plete teaching video of each knowledge point (full coverage of } \\
\text { the course content), encourages the use of micro-video teaching } \\
\text { video, each video does not exceed } 15 \text { minutes }\end{array}$ & Multimedia & Must choose \\
\hline Courseware & $\begin{array}{l}\text { Provide students with teaching courseware for students to learn } \\
\text { by themselves }\end{array}$ & Multimedia & Must choose \\
\hline $\begin{array}{l}\text { teaching } \\
\text { sample }\end{array}$ & $\begin{array}{l}\text { Encourage the use of case teaching and provide a number of text } \\
\text { cases or video cases of no less than } 10 \text { for students to study }\end{array}$ & Text & Must choose \\
\hline Expert lecture & $\begin{array}{l}\text { Provide students with front-end lectures related to the course, or } \\
\text { video network links, no less than } 4\end{array}$ & Video & Must choose \\
\hline $\begin{array}{l}\text { Module } \\
\text { summary }\end{array}$ & Summarize the contents of the module & Text & Must choose \\
\hline Practice / & Key and difficult content books provide relevant exercises and & Text & Must choose \\
\hline
\end{tabular}




\begin{tabular}{|l|l|l|l|}
\hline self-test & $\begin{array}{l}\text { answers: each module needs to provide corresponding online tests } \\
\text { to support learners online self-test: provide training, creative } \\
\text { work or tests that are compatible with high-level learning objec- } \\
\text { tives. }\end{array}$ & $\begin{array}{l}\text { Provide resources such as electronic documents/reference } \\
\text { books/websites related to the content of this module for learners } \\
\text { to read and study independently }\end{array}$ & Text \\
\hline $\begin{array}{l}\text { Student } \\
\text { resources }\end{array}$ & Must choose \\
\hline
\end{tabular}

5) Data analysis module: In the data analysis of the cloud classroom, system construction involves two modules of the overall situation of the cloud classroom and the use of the cloud classroom. The overall situation of the cloud classroom includes the establishment of the curriculum [15]. Three small modules, such as the construction of the classroom and the construction of resources, the use of the cloud classroom includes two small modules, such as teacher participation and statistical analysis of student learning behavior, are shown in Figure 5. The data visualization system of the cloud classroom can be divided into five visual modules: Curriculum, classroom, resources, teachers and students.

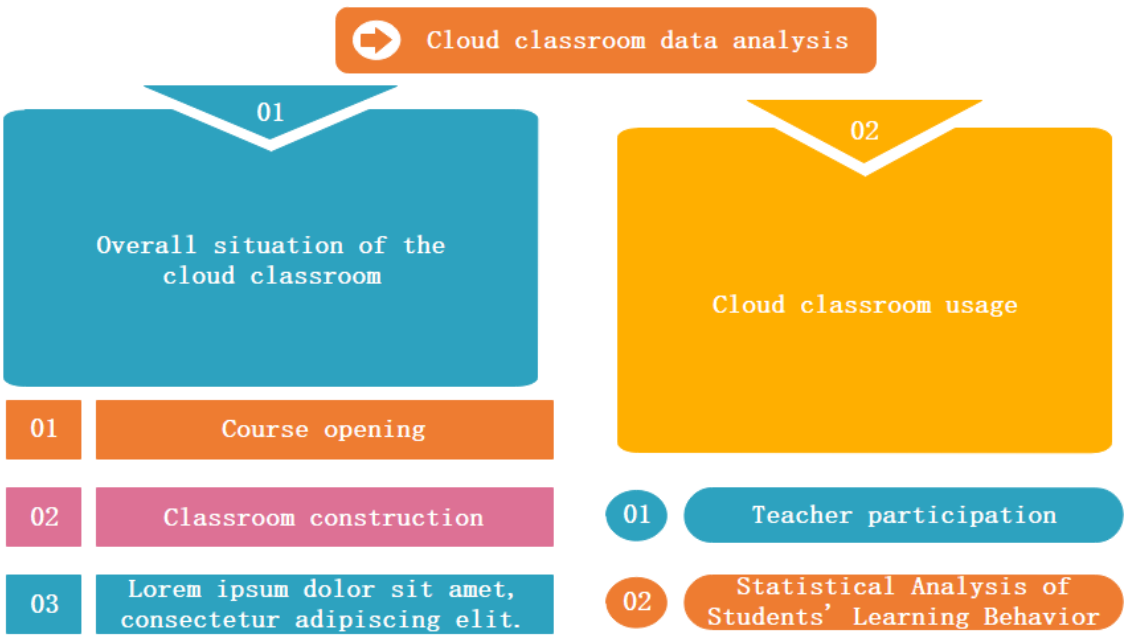

Fig. 5. Data analysis module diagram.

6) Course recommendation module design: The course recommendation includes two recommendations: recommendations for hot courses and recommendations for personalized courses based on collaborative filtering algorithms. In this module, the current hotspots will be selected by counting the number of times the course is used, and hotspots will be recommended on the homepage [16]. It also uses the correlation algorithm to judge the neighboring users according to the search content of each user, and recommend suitable courses for users according to the search content of similar users. 


\section{Conclusion}

A cloud classroom is an efficient, convenient and real-time interactive classroom teaching tool that has emerged in the context of big data. It has the characteristics and advantages of information technology, and it has received widespread attention as soon as it emerged. With the widespread popularity of the mobile Internet and smart terminals, Internet + has become a new trend in economic development. Wisdom education and personalized learning have appeared in our study lives. Under the dual pressure of work and study, the realization of individualized recommendation of educational resources has become a primary problem that needs to be solved in wisdom education. A personalized recommendation system is a key technology to solve the problem of cognitive overload or voyage when users are learning online. This approach can be used from primary to tertiary education, and even in prisons. This paper studies the personalized curriculum recommendation system based on a user collaborative filtering algorithm. The preliminary recommendation and quick recommendation of the desired course have been achieved, which lay the foundations for individualized teaching.

\section{$5 \quad$ References}

[1] Liu Shaojuan. (2015). Cloud Curriculum: The Pursuit of Personalized Education in the Age of Big Data, Modern Education, no.3, pp.135-137.

[2] Kong Nan. (2013). The era of intelligent education or the future, People's Daily Overseas Edition, vol.6. Available: http://www.people.com.cn

[3] Wang Shixin. (2019). Analysis of the educational concept and construction development of Internet + Technician Education, Science and Education Wenhui (late issue), no.2, pp.89-93.

[4] Guan Beiguang. (2014). The Teaching Method of Physical Education in the Cloud Course Era and the Strategy of Teacher Professional Development, Journal of Leshan Teachers College, vol.29, no.12, pp113-115.

[5] Cao Wenzhuo. (2016). Research on Application of Learning Analysis Based on Cloud Classroom Learning Platform [D]. Wuhan: Central China Normal University, pp.16-16.

[6] Kang Ling, Wang Wenjing. (2019). Research on College Students' Innovation and Entrepreneurship Education Based on Internet + Background [J]. China Management Informationization.

[7] Lu Yao. (2016). Design and implementation of data visualization and exploration system [D]. Zhejiang University.

[8] Wang Xiaotong, Li Xian, Yuan Yuan. (2019). Recommendation algorithm based on factorization machine and hidden Markov, Computer Technology and Development, vol.29, no.6, June, pp.85-89.

[9] Sung K M, Seongcheol K. (2018). Factors influencing willingness to provide personal information for personalized recommendations, Computers in Human Behavior, S074756321830308X-.

[10] Yang Huan. (2017). Research on cloud classroom teaching strategy based on mobile terminal, M. S. thesis, Central China Normal University, Wuhan, China. 
[11] Zeng You. (2014). Research on the concept of data visualization under the background of big data era, M. S. thesis, Zhejiang University, Zhejiang, China.

[12] M. James C. Crabbe, Lucy O’Rorke, Eamonn Egan, Ali Hadawi. (2015). Open Futures: An Enquiry- and Skills- Based Educational Programme Developed for Primary Education, and its use in Tertiary Education, Journal of Pedagogic Development, no.5, pp.3-8.

[13] M. James C. Crabbe. (2016). Education for Offenders in Prison, Journal of Pedagogic Development, vol.6, no.3, pp.3-7.

[14] Orazbayev, B.; Santeyeva, S.; Zhumadillayeva, A.; Dyussekeyev, K.; Agarwal, R.K.; Yue, X.-G.; Fan, J. (2019). Sustainable Waste Management Drilling Process in Fuzzy Environment, Sustainability, no.11, pp.69-95. https://doi.org/10.3390/su11246995

[15] Xiao-Guang Yue, Sanjay K. Boddhu, Ying Lu, Fuyuan Xiao, Tarita Memonen, Maia V. Cañiv. (2016). Gas Outburst Prediction Based on OD Algorithm, Recent Patents on Computer Science, vol.9, no.1, pp.25-39. https://doi.org/10.2174/221327590866615021819445 $\underline{0}$

[16] Muhamad Fitra Kacamarga, Arif Budiarto, Bens Pardamean. (2020). A Platform for Electronic Health Record Sharing in Environments with Scarce Resource Using Cloud Computing, International Journal of Online and Biomedical Engineering (iJOE). vol.16, no.09, pp.63-77. https://doi.org/10.3991/ijoe.v16i09.13187

\section{Authors}

Jing Gao is the Professor and Dean of School of General Education, Wuhan Business University, Wuhan, China. 1441691661@qq.com

Xiao-Guang Yue is the Adjunct Professor at European University Cyprus. xgyue@ieti.net

Lulu Hao is working at the School of General Education, Wuhan Business University, Wuhan, China.

M. James C. Crabbe is a Supernumerary Fellow of Wolfson College, Oxford University. He is an Emeritus Professor of Biochemistry, a '100 Talents' Special Visiting Professor at Shanxi University (China), Guest Professor at Wuhan Business University (China) and Honorary Professor at Changchun University of Science \& Technology (China). He is President of the International Engineering \& Technology Institute. james.crabbe@wolfson.ox.ac.uk

Otilia Manta is working at the Romanian Academy, Center for Financial and Monetary Research and Romanian-American University, Bucharest, Romania. otlia.manta@rgic.ro

Nelson Duarte is working at the CIICESI, ESTG, Politécnico do Porto, Felgueiras, Portugal. nduarte@estg.ipp.pt

Article submitted 2020-09-04. Resubmitted 2020-10-04. Final acceptance 2020-10-05. Final version published as submitted by the authors. 